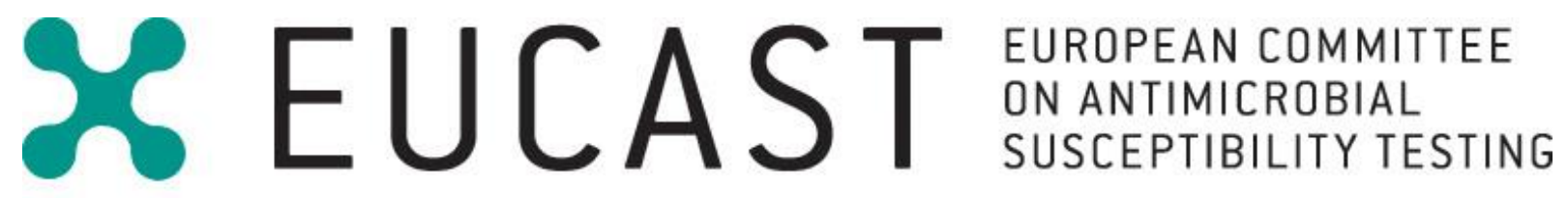

European Society of Clinical Microbiology and Infectious Diseases

\title{
Antimicrobial susceptibility testing
}

\section{EUCAST disk diffusion method}

\author{
Version 7.0 \\ January 2019
}




\begin{tabular}{|c|c|c|}
\hline & ents & Page \\
\hline & $\underline{\text { Changes from previous version }}$ & \\
\hline & Abbreviations and Terminology & \\
\hline 1 & $\underline{\text { Introduction }}$ & 5 \\
\hline 2 & Preparation and storage of media & 6 \\
\hline 3 & Preparation of inoculum & 8 \\
\hline 4 & Inoculation of agar plates & 10 \\
\hline 5 & Application of antimicrobial disks & 11 \\
\hline 6 & Incubation of plates & 12 \\
\hline 7 & Examination of plates after incubation & 14 \\
\hline 8 & Measurement of zones and interpretation of susceptibility & 15 \\
\hline 9 & Quality control & 17 \\
\hline & Appendix A & 20 \\
\hline
\end{tabular}




\section{Changes from previous version (v. 6.0)}

\begin{tabular}{|l|l|}
\hline Section & Change \\
\hline $\begin{array}{l}\text { Table 1, Table 3, } \\
\mathbf{8 . 9 . 3}\end{array}$ & New taxonomy: Enterobacteriaceae changed to Enterobacterales. \\
\hline Table 1, Table 3 & Aeromonas spp. added \\
\hline $\mathbf{8 . 9 . 2}$ & $\begin{array}{l}\text { Instructions for reading of trimethoprim-sulfamethoxazole for } \\
\text { Aeromonas spp. added. }\end{array}$ \\
\hline
\end{tabular}




\begin{tabular}{|c|c|}
\hline \multicolumn{2}{|c|}{ Abbreviations and terminology } \\
\hline ATCC & $\begin{array}{l}\text { American Type Culture Collection } \\
\text { http://www.atcc.org }\end{array}$ \\
\hline CCUG & $\begin{array}{l}\text { Culture Collection University of Gothenburg } \\
\text { http://www.ccug.se }\end{array}$ \\
\hline CECT & $\begin{array}{l}\text { Colección Española de Cultivos Tipo } \\
\text { http://www.cect.org }\end{array}$ \\
\hline CFU & Colony Forming Unit \\
\hline CIP & $\begin{array}{l}\text { Collection de I'Institut Pasteur } \\
\text { https://www.pasteur.fr/en/public-health/crbip/collections/collection-institut- } \\
\text { pasteur-cip NEW ADDRESS }\end{array}$ \\
\hline DSM & $\begin{array}{l}\text { Bacterial cultures from Deutsche Sammlung von Mikroorganismen und } \\
\text { Zellkulturen (DSMZ) have DSM numbers } \\
\text { https://www.dsmz.de }\end{array}$ \\
\hline ESBL & Extended-Spectrum $\beta$-Lactamase \\
\hline EUCAST & $\begin{array}{l}\text { European Committee on Antimicrobial Susceptibility Testing } \\
\text { http://www.eucast.org }\end{array}$ \\
\hline $\mathrm{MH}$ & Mueller-Hinton agar \\
\hline $\mathrm{MH}-\mathrm{F}$ & $\begin{array}{l}\text { Mueller-Hinton agar for Fastidious organisms (MH supplemented with } 5 \% \\
\text { defibrinated horse blood and } 20 \mathrm{mg} / \mathrm{L} \beta-\mathrm{NAD} \text { ) }\end{array}$ \\
\hline MIC & Minimum Inhibitory Concentration \\
\hline MRSA & Methicillin Resistant Staphylococcus aureus (with mecA or mecC gene) \\
\hline NCTC & $\begin{array}{l}\text { National Collection of Type Cultures } \\
\text { https://www.phe-culturecollections.org.uk/collections/nctc NEW ADDRESS }\end{array}$ \\
\hline B-NAD & B-Nicotinamide Adenine Dinucleotide \\
\hline QC & Quality Control \\
\hline Saline & A $0.85 \%$ solution of $\mathrm{NaCl}$ in water $(8.5 \mathrm{~g} / \mathrm{L})$ \\
\hline
\end{tabular}




\begin{tabular}{|l|l|}
\hline 1 & Introduction \\
\hline $\begin{array}{l}\text { Disk diffusion is one of the oldest approaches to antimicrobial susceptibility testing } \\
\text { and remains one of the most widely used antimicrobial susceptibility testing } \\
\text { methods in routine clinical laboratories. It is suitable for testing the majority of } \\
\text { bacterial pathogens, including the more common fastidious bacteria, is versatile in } \\
\text { the range of antimicrobial agents that can be tested and requires no special } \\
\text { equipment. } \\
\text { In common with several other disk diffusion techniques, the EUCAST method is a } \\
\text { standardised method based on the principles defined in the report of the } \\
\text { International Collaborative Study of Antimicrobial Susceptibility Testing, 1972, and } \\
\text { the experience of expert groups worldwide. } \\
\text { The zone diameter breakpoints in the EUCAST disk diffusion method are calibrated } \\
\text { to the harmonised European MIC breakpoints that are published by EUCAST and } \\
\text { are freely available from the EUCAST website (http://www.eucast.org). } \\
\text { As with all standardised methods, the described technique must be followed without } \\
\text { modification in order to produce reliable results. }\end{array}$ \\
\hline
\end{tabular}




\section{$2 \quad$ Preparation and storage of media}

2.1 Prepare Mueller-Hinton (MH) agar according to the manufacturer's instructions, with supplementation for fastidious organisms as indicated in Table 1. Preparation and addition of supplements are described in detail at http://www.eucast.org.

2.2 The medium should have a level depth of $4.0 \pm 0.5 \mathrm{~mm}$ (approximately $25 \mathrm{~mL}$ in a 90 $\mathrm{mm}$ circular plate, $31 \mathrm{~mL}$ in a $100 \mathrm{~mm}$ circular plate, $71 \mathrm{~mL}$ in a $150 \mathrm{~mm}$ circular plate, $40 \mathrm{~mL}$ in a $100 \mathrm{~mm}$ square plate). Ascertain that a correct volume, based on the true dimensions of the Petri dish in use, is calculated. Plate dimensions may differ between manufacturers.

2.3 The surface of the agar should be dry before use. No drops of water should be visible on the surface of the agar or inside the lid. If necessary, dry plates either at $20-25^{\circ} \mathrm{C}$ overnight, or at $35^{\circ} \mathrm{C}$, with the lid removed, for $15 \mathrm{~min}$. Do not over-dry plates.

2.4 Store plates prepared in-house at $4-8^{\circ} \mathrm{C}$.

2.5 For plates prepared in-house, plate drying, storage conditions and shelf life should be determined as part of the laboratory quality assurance programme.

2.6 Commercially prepared plates should be stored as recommended by the manufacturer and used within the labelled expiry date.

2.7 For agar plates (commercially or in-house prepared) stored in plastic bags or sealed containers, it may be necessary to dry the plates prior to use (see section 2.3). This is to avoid excess moisture, which may result in problems with fuzzy zone edges and/or haze within zones. 


\begin{tabular}{|c|c|c|}
\hline Table 1 & \multicolumn{2}{|c|}{ Media for antimicrobial susceptibility testing } \\
\hline \multicolumn{2}{|l|}{ Organism } & Medium \\
\hline \multicolumn{2}{|c|}{ Enterobacterales } & $\mathrm{MH}$ agar \\
\hline \multicolumn{2}{|c|}{ Pseudomonas spp. } & $\mathrm{MH}$ agar \\
\hline \multicolumn{2}{|c|}{ Stenotrophomonas maltophilia } & $\mathrm{MH}$ agar \\
\hline \multicolumn{2}{|c|}{ Acinetobacter spp. } & $\mathrm{MH}$ agar \\
\hline \multicolumn{2}{|c|}{ Staphylococcus spp. } & $\mathrm{MH}$ agar \\
\hline \multicolumn{2}{|c|}{ Enterococcus spp. } & $\mathrm{MH}$ agar \\
\hline \multicolumn{2}{|c|}{ Streptococcus groups A, B, C and G } & MH-F agar $^{1}$ \\
\hline \multicolumn{2}{|c|}{ Streptococcus pneumoniae } & MH-F agar $^{1}$ \\
\hline \multicolumn{2}{|c|}{ Viridans group streptococci } & MH-F agar $^{1}$ \\
\hline \multicolumn{2}{|c|}{ Haemophilus influenzae } & MH-F agar $^{1}$ \\
\hline \multicolumn{2}{|c|}{ Moraxella catarrhalis } & MH-F agar $^{1}$ \\
\hline \multicolumn{2}{|c|}{ Listeria monocytogenes } & MH-F agar ${ }^{1}$ \\
\hline \multicolumn{2}{|c|}{ Pasteurella multocida } & MH-F agar ${ }^{1}$ \\
\hline \multicolumn{2}{|c|}{ Campylobacter jejuni and coli } & MH-F $\operatorname{agar}^{1}$ (see Appendix A) \\
\hline \multicolumn{2}{|c|}{ Corynebacterium spp. } & MH-F agar ${ }^{1}$ \\
\hline \multicolumn{2}{|c|}{ Aerococcus sanguinicola and urinae } & MH-F agar ${ }^{1}$ \\
\hline \multicolumn{2}{|c|}{ Kingella kingae } & MH-F agar ${ }^{1}$ \\
\hline \multicolumn{2}{|c|}{ Aeromonas spp. } & $\mathrm{MH}$ agar \\
\hline \multicolumn{2}{|c|}{ Other fastidious organisms } & Pending \\
\hline
\end{tabular}

${ }^{1} \mathrm{MH}+5 \%$ mechanically defibrinated horse blood $+20 \mathrm{mg} / \mathrm{L} \beta-\mathrm{NAD}$ 


\section{$3 \quad$ Preparation of inoculum}

3.1 Use the direct colony suspension method to make a suspension of the organism in saline to the density of a 0.5 McFarland turbidity standard (Table 2), approximately corresponding to $1-2 \times 10^{8} \mathrm{CFU} / \mathrm{mL}$ for Escherichia coli.

The direct colony suspension method is appropriate for all organisms, including fastidious organisms in Table 1.

3.2 Use a sterile loop or a cotton swab to pick colonies from an overnight culture on nonselective media. Use several morphologically similar colonies (when possible) to avoid selecting an atypical variant. Suspend the colonies in saline and mix to an even turbidity.

3.3 Adjust the density of the organism suspension to $0.5 \mathrm{McF}$ arland by adding saline or more bacteria. A denser inoculum will result in reduced zones of inhibition and a decreased inoculum will have the opposite effect.

3.3.1 It is recommended that a photometric device is used to adjust the density of the suspension. The photometric device must be calibrated against a 0.5 McFarland standard according to the manufacturer's instruction.

3.3.2 Alternatively, the density of the suspension can be compared visually to a $0.5 \mathrm{McF}$ arland turbidity standard. To aid comparison, compare the test and standard against a white background with black lines.

Streptococcus pneumoniae is, preferably, suspended from a blood agar plate to the density of a 0.5 McFarland standard. When Streptococcus pneumoniae is suspended from a chocolate agar plate, the inoculum must be equivalent to a $1.0 \mathrm{McF}$ arland standard.

3.4 The suspension should optimally be used within $15 \mathrm{~min}^{1}$ and always within $60 \mathrm{~min}$ of preparation.

${ }^{1}$ Part of the 15-15-15 minute rule: use the inoculum suspension within 15 minutes of preparation, apply disks within 15 minutes of inoculation and incubate plates within 15 minutes of disk application. 


\section{Table 2 Preparation of 0.5 McFarland turbidity standard}

Add $0.5 \mathrm{~mL}$ of $0.048 \mathrm{~mol} / \mathrm{L} \mathrm{BaCl}_{2}\left(1.175 \% \mathrm{w} / \mathrm{v} \mathrm{BaCl} 2 \cdot 2 \mathrm{H}_{2} 0\right)$ to $99.5 \mathrm{~mL}$ of 0.18 $\mathrm{mol} / \mathrm{L}(0.36 \mathrm{~N}) \mathrm{H}_{2} \mathrm{SO}_{4}(1 \% \mathrm{v} / \mathrm{v})$ and mix thoroughly.

$2 \quad$ Check the density of the suspension in a spectrophotometer with a $1 \mathrm{~cm}$ light path and matched cuvettes. The absorbance at $625 \mathrm{~nm}$ should be in the range 0.08 to 0.13 .

3 Distribute the suspension into tubes of the same size as those used for bacterial inoculum suspensions. Seal the tubes.

$4 \quad$ Store sealed standards in the dark at room temperature.

$5 \quad$ Mix the standard thoroughly on a vortex mixer immediately before use.

6 Renew standards or check their absorbance after storage for 6 months. 


\begin{tabular}{|c|c|}
\hline 4 & Inoculation of agar plates \\
\hline 4.1 & Make sure that agar plates are at room temperature prior to inoculation. \\
\hline 4.2 & $\begin{array}{l}\text { Optimally, use the adjusted inoculum suspension within } 15 \min ^{1} \text { of preparation. } \\
\text { The suspension must always be used within } 60 \text { min of preparation. }\end{array}$ \\
\hline 4.3 & Dip a sterile cotton swab into the suspension. \\
\hline 4.3 .1 & $\begin{array}{l}\text { To avoid over-inoculation of Gram-negative bacteria, remove excess } \\
\text { fluid by pressing and turning the swab against the inside of the tube. }\end{array}$ \\
\hline 4.3.2 & $\begin{array}{l}\text { For Gram-positive bacteria, do not press or turn the swab against the } \\
\text { inside of the tube. }\end{array}$ \\
\hline 4.4 & $\begin{array}{l}\text { When inoculating several agar plates with the same inoculum suspension, } \\
\text { repeat the procedure in section } 4.3 \text { for each agar plate. }\end{array}$ \\
\hline 4.5 & $\begin{array}{l}\text { Plates can be inoculated either by swabbing in three directions or by using an } \\
\text { automatic plate rotator. Spread the inoculum evenly over the entire agar surface } \\
\text { ensuring that there are no gaps between streaks. }\end{array}$ \\
\hline 4.5.1 & $\begin{array}{l}\text { For Gram-positive bacteria, take particular care to ensure that there are } \\
\text { no gaps between streaks. }\end{array}$ \\
\hline 4.6 & $\begin{array}{l}\text { Apply disks within } 15 \min ^{1} \text { of inoculation. } \\
\text { If inoculated plates are left at room temperature for prolonged periods of time } \\
\text { before the disks are applied, the organism may begin to grow, resulting in } \\
\text { erroneous reduction in sizes of inhibition zone diameters. }\end{array}$ \\
\hline
\end{tabular}

'Part of the 15-15-15 minute rule: use the inoculum suspension within 15 minutes of preparation, apply disks within 15 minutes of inoculation and incubate plates within 15 minutes of disk application. 


\section{$5 \quad$ Application of antimicrobial disks}

5.1 The required disk contents are listed in the Breakpoint and Quality Control Tables at http://www.eucast.org.

5.2 Allow disks to reach room temperature before opening cartridges or containers used for disk storage. This is to prevent condensation, leading to rapid deterioration of some agents.

5.3 Apply disks firmly to the surface of the inoculated agar plate within 15 minutes of inoculation ${ }^{1}$. Disks must be in close and even contact with the agar surface and must not be moved once they have been applied as the initial diffusion of antimicrobial agents from disks is very rapid.

5.4 The number of disks on a plate should be limited to avoid overlapping of zones and interference between agents. It is important that zone diameters can be reliably measured. The maximum number of disks depends on the organism and the selection of disks. Normally 6 and 12 disks are the maximum possible number on a 90 and $150 \mathrm{~mm}$ circular plate, respectively.

5.4.1 To be able to detect inducible clindamycin resistance in staphylococci and streptococci, the erythromycin and clindamycin disks must be placed at a distance of $12-20 \mathrm{~mm}$ from edge to edge for staphylococci and $12-16 \mathrm{~mm}$ from edge to edge for streptococci.

5.5 Loss of potency of antimicrobial agents in disks results in reduced inhibition zone diameters and is a common source of error. The following are essential:

5.5.1 Store disks, including those in dispensers, in sealed containers with a moisture-indicating desiccant and protected from light (some agents, including metronidazole, chloramphenicol and the fluoroquinolones, are inactivated by prolonged exposure to light).

5.5.2 Store disk stocks according the manufacturers' instructions. Some agents are more labile than others (e.g. amoxicillin-clavulanic acid, cefaclor and carbapenems) and specific recommendations may be available from the manufacturers.

5.5.3 Store working supplies of disks according to the manufacturers' instructions. Once disk containers have been opened, disks should be used within the time limit specified by the manufacturer.

5.5.4 Discard disks on the manufacturer's expiry date shown on the container.

5.5.5 Perform frequent quality control (see Section 9) of working supplies to control that the antimicrobial disks have not lost potency during storage.

${ }^{1}$ Part of the 15-15-15 minute rule: use the inoculum suspension within 15 minutes of preparation, apply disks within 15 minutes of inoculation and incubate plates within 15 minutes of disk application. 


\begin{tabular}{|c|c|}
\hline 6 & Incubation of plates \\
\hline 6.1 & $\begin{array}{l}\text { Invert agar plates and make sure disks do not fall off the agar surface. Incubate } \\
\text { plates within } 15 \mathrm{~min}^{1} \text { of disk application. If the plates are left at room temperature } \\
\text { after disks have been applied, pre-diffusion may result in erroneously large zones of } \\
\text { inhibition. }\end{array}$ \\
\hline 6.2 & $\begin{array}{l}\text { Stacking plates in the incubator may affect results due to uneven heating. The } \\
\text { efficiency of incubators varies and therefore the control of incubation, including } \\
\text { appropriate number of plates in any one stack, should be determined as part of the } \\
\text { laboratory's quality assurance programme. For most incubators, a maximum of five } \\
\text { plates per stack is appropriate. }\end{array}$ \\
\hline 6.3 & Incubate plates in the conditions shown in Table 3. \\
\hline 6.3 .1 & $\begin{array}{l}\text { Incubation beyond the recommended time limits should not be performed as } \\
\text { this may result in growth within inhibition zones and reporting isolates as false } \\
\text { resistant. }\end{array}$ \\
\hline 6.3 .2 & $\begin{array}{l}\text { With glycopeptide susceptibility tests on Enterococcus spp. resistant colonies } \\
\text { may not be visible until plates have been incubated for } 24 \mathrm{~h} \text {. However, plates } \\
\text { may be examined after } 16-20 \mathrm{~h} \text { and any resistance reported, but plates of } \\
\text { isolates appearing susceptible must be re-incubated and reread at } 24 \mathrm{~h} \text {. }\end{array}$ \\
\hline
\end{tabular}

${ }^{1}$ Part of the 15-15-15 minute rule: use the inoculum suspension within 15 minutes of preparation, apply disks within 15 minutes of inoculation and incubate plates within 15 minutes of disk application. 


\begin{tabular}{|c|c|c|}
\hline Table 3 & \multicolumn{2}{|c|}{$\begin{array}{l}\text { Incubation conditions for antimicrobial susceptibility } \\
\text { test plates }\end{array}$} \\
\hline \multicolumn{2}{|l|}{ Organism } & Incubation conditions \\
\hline \multicolumn{2}{|c|}{ Enterobacterales } & $35 \pm 1^{\circ} \mathrm{C}$ in air for $18 \pm 2 \mathrm{~h}$ \\
\hline \multicolumn{2}{|c|}{ Pseudomonas spp. } & $35 \pm 1^{\circ} \mathrm{C}$ in air for $18 \pm 2 \mathrm{~h}$ \\
\hline \multicolumn{2}{|c|}{ Stenotrophomonas maltophilia } & $35 \pm 1^{\circ} \mathrm{C}$ in air for $18 \pm 2 \mathrm{~h}$ \\
\hline \multicolumn{2}{|c|}{ Acinetobacter spp. } & $35 \pm 1^{\circ} \mathrm{C}$ in air for $18 \pm 2 \mathrm{~h}$ \\
\hline \multicolumn{2}{|c|}{ Staphylococcus spp. } & $35 \pm 1^{\circ} \mathrm{C}$ in air for $18 \pm 2 \mathrm{~h}$ \\
\hline \multicolumn{2}{|c|}{ Enterococcus spp. } & $35 \pm 1^{\circ} \mathrm{C}$ in air for $18 \pm 2 \mathrm{~h}$ ( $24 \mathrm{~h}$ for glycopeptides) \\
\hline \multicolumn{2}{|c|}{ Aeromonas spp. } & $35 \pm 1^{\circ} \mathrm{C}$ in air for $18 \pm 2 \mathrm{~h}$ \\
\hline \multicolumn{2}{|c|}{ Streptococcus groups $A, B, C$ and $G$} & $35 \pm 1^{\circ} \mathrm{C}$ in $4-6 \% \mathrm{CO}_{2}$ in air for $18 \pm 2 \mathrm{~h}$ \\
\hline \multicolumn{2}{|c|}{ Streptococcus pneumoniae } & $35 \pm 1^{\circ} \mathrm{C}$ in $4-6 \% \mathrm{CO}_{2}$ in air for $18 \pm 2 \mathrm{~h}$ \\
\hline \multicolumn{2}{|c|}{ Viridans group streptococci } & $35 \pm 1^{\circ} \mathrm{C}$ in $4-6 \% \mathrm{CO}_{2}$ in air for $18 \pm 2 \mathrm{~h}$ \\
\hline \multicolumn{2}{|c|}{ Haemophilus influenzae } & $35 \pm 1^{\circ} \mathrm{C}$ in $4-6 \% \mathrm{CO}_{2}$ in air for $18 \pm 2 \mathrm{~h}$ \\
\hline \multicolumn{2}{|c|}{ Moraxella catarrhalis } & $35 \pm 1^{\circ} \mathrm{C}$ in $4-6 \% \mathrm{CO}_{2}$ in air for $18 \pm 2 \mathrm{~h}$ \\
\hline \multicolumn{2}{|c|}{ Listeria monocytogenes } & $35 \pm 1^{\circ} \mathrm{C}$ in $4-6 \% \mathrm{CO}_{2}$ in air for $18 \pm 2 \mathrm{~h}$ \\
\hline \multicolumn{2}{|c|}{ Pasteurella multocida } & $35 \pm 1^{\circ} \mathrm{C}$ in $4-6 \% \mathrm{CO}_{2}$ in air for $18 \pm 2 \mathrm{~h}$ \\
\hline \multicolumn{2}{|c|}{ Campylobacter jejuni and coli } & See Appendix A \\
\hline \multicolumn{2}{|c|}{ Corynebacterium spp. } & $\begin{array}{l}35 \pm 1^{\circ} \mathrm{C} \text { in } 4-6 \% \mathrm{CO}_{2} \text { in air for } 18 \pm 2 \mathrm{~h} \text {. Isolates with } \\
\text { insufficient growth after } 16-20 \mathrm{~h} \text { are re-incubated immediately } \\
\text { and inhibition zones read after a total of } 40-44 \mathrm{~h} \text { incubation. }\end{array}$ \\
\hline \multicolumn{2}{|c|}{ Aerococcus sanguinicola and urinae } & $\begin{array}{l}35 \pm 1^{\circ} \mathrm{C} \text { in } 4-6 \% \mathrm{CO}_{2} \text { in air for } 18 \pm 2 \mathrm{~h} \text {. Isolates with } \\
\text { insufficient growth after } 16-20 \mathrm{~h} \text { are re-incubated immediately } \\
\text { and inhibition zones read after a total of } 40-44 \mathrm{~h} \text { incubation. }\end{array}$ \\
\hline \multicolumn{2}{|c|}{ Kingella kingae } & $\begin{array}{l}35 \pm 1^{\circ} \mathrm{C} \text { in } 4-6 \% \mathrm{CO}_{2} \text { in air for } 18 \pm 2 \mathrm{~h} \text {. Isolates with } \\
\text { insufficient growth after } 16-20 \mathrm{~h} \text { are re-incubated immediately } \\
\text { and inhibition zones read after a total of } 40-44 \mathrm{~h} \text { incubation. }\end{array}$ \\
\hline \multicolumn{2}{|c|}{ Other fastidious organisms } & Pending \\
\hline
\end{tabular}




\section{$7 \quad$ Examination of plates after incubation}

7.1 A correct inoculum and satisfactorily streaked plates should result in a confluent lawn of growth.

7.1.1 If individual colonies can be seen, the inoculum is too light and the test must be repeated.

7.2 The growth should be evenly distributed over the agar surface to achieve uniformly circular (non-jagged) inhibition zones.

7.3 Check that inhibition zones for quality control strains are within acceptable ranges (http://www.eucast.org). 
8.1 For all agents (unless otherwise stated in section 8.9), the zone edge should be read at the point of complete inhibition as judged by the naked eye with the plate held about $30 \mathrm{~cm}$ from the eye.

8.2 Read un-supplemented plates from the back with reflected light and the plate held above a dark background.

8.3 Read supplemented plates from the front with the lid removed and with reflected light.

8.4 Do not use transmitted light (plate held up to light) or a magnifying glass, unless otherwise stated (see section 8.9).

8.5 Measure the inhibition zone diameters to the nearest millimetre with a ruler or a calliper.

8.5.1 If an automated zone reader is used, it must be calibrated to manual reading.

8.6 Interpret zone diameters into susceptibility categories according to the current breakpoint tables at http://www.eucast.org.

8.7 If templates are used for interpreting zone diameters, the plate is placed over the template and zones interpreted according to the EUCAST breakpoints marked on the template. Make certain that the breakpoints used are in accordance with the latest version of the EUCAST breakpoint tables. A program for preparation of templates is freely available from http://bsac.org.uk/susceptibility/template-program.

8.8 Several examples of pictures showing reading of inhibition zone diameters are available in the Reading Guide at http://www.eucast.org. This document also includes reading instructions for specific organism-antimicrobial agent combinations.

8.9 Specific reading instructions:

8.9.1 In case of double zones, or distinct colonies within zones, check for purity and repeat the test if necessary. If cultures are pure, colonies within zones should be taken into account when measuring the diameter.

8.9.2 For trimethoprim and trimethoprim-sulfamethoxazole, faint growth up to the disk may appear due to antagonists in the medium. Such growth should be ignored and the zone diameter measured at the more obvious zone edge.

For Stenotrophomonas maltophilia with trimethoprim-sulfamethoxazole, an isolate showing any sign of inhibition zone $\geq$ the susceptible breakpoint should be reported susceptible. Note that there may be substantial growth within zones. Read as no zone only if there is growth up to the disk and no sign of an inhibition zone.

For Aeromonas spp. with trimethoprim-sulfamethoxazole, read the obvious zone edge and disregard haze or growth within the inhibition zone. If there is an obvious inner zone edge, read the inhibition zone as the inner zone. 
8.9.3 For Enterobacterales with ampicillin, ampicillin-sulbactam and amoxicillinclavulanic acid, ignore growth that may appear as a thin film producing an inner zone on some batches of Mueller-Hinton agar.

8.9.4 For Escherichia coli with mecillinam, ignore isolated colonies within the inhibition zone.

8.9.5 For Proteus spp., ignore swarming and read inhibition of growth.

8.9.6 For Staphylococcus aureus with benzylpenicillin, examine the zone edge closely from the front of the plate with the plate held up to light (transmitted light). Isolates with inhibition zone diameters $\geq$ the susceptible breakpoint, but with sharp zone edges should be reported resistant.

8.9.7 When using cefoxitin for the detection of methicillin resistance in Staphylococcus aureus, measure the obvious zone, and examine zones carefully in good light to detect colonies within the zone of inhibition. These may be either a contaminating species or the expression of heterogeneous methicillin resistance.

8.9.8 Read linezolid susceptibility tests on staphylococci from the back with the plate held up to light (transmitted light).

8.9.9 For enterococci with vancomycin, examine the zone edge closely from the front of the plate with the plate held up to light (transmitted light). Fuzzy zone edges and colonies within zone indicate vancomycin resistance and should be investigated further. Isolates must not be reported susceptible before $24 \mathrm{~h}$ incubation.

8.9.10 For haemolytic streptococci, read inhibition of growth and not inhibition of haemolysis. $\beta$-Haemolysis is usually free from growth, whereas $\alpha$-haemolysis and growth usually coincide. Tilt the plate back and forth to better differentiate between haemolysis and growth.

8.9.11 For Escherichia coli with fosfomycin, ignore isolated colonies within the inhibition zone and read the outer zone edge. 


\section{$9 \quad$ Quality control}

9.1 Use the quality control (QC) strains specified in Table 4 to monitor the performance of the test. Principal recommended control strains are typical susceptible strains, but resistant strains can also be used to confirm that the method will detect resistance mediated by known resistance mechanisms (Extended QC, Table 5). QC strains may be purchased from culture collections or from commercial sources.

9.1.1 To control the inhibitor component of $\beta$-lactam- $\beta$-lactamase inhibitor combination disks, specific $\beta$-lactamase-producing strains are recommended (Table 4). This should be part of the routine QC. The active component is checked with a susceptible QC strain.

9.2 Store control strains under conditions that will maintain viability and organism characteristics. Storage on beads at $-70^{\circ} \mathrm{C}$ in glycerol broth (or commercial equivalent) is a convenient method. Non-fastidious organisms can be stored at $-20^{\circ} \mathrm{C}$. Two vials of each control strain should be stored, one as an in-use supply and the other as an archive for replenishment of the in-use vial when required.

9.3 Each week, subculture a bead from the in-use vial onto appropriate non-selective media and check for purity. From this pure culture, prepare one subculture on each day of the week. For fastidious organisms that will not survive on plates for five to six days, subculture the strain daily for no more than one week.

When subculturing a control strain, use several colonies to avoid selecting a mutant.

9.4 Check that results for control strains are within acceptable ranges in EUCAST QC Tables at http://www.eucast.org.

9.4.1 In EUCAST quality control tables, both ranges and targets are listed. Repeat testing of EUCAST QC strains should yield zone diameter values randomly distributed within the recommended ranges. If the number of tests is $\geq 10$, the mean zone diameter should be close to the target value $( \pm 1 \mathrm{~mm}$ from the target value).

9.5 Use the recommended routine QC strains to monitor test performance.

Control tests should be set up and checked daily, or at least four times per week for antibiotics which are part of routine panels.

Each day that tests are set up, examine the results of the last 20 consecutive tests. Examine results for trends and for zones falling consistently above or below the target. If two or more of 20 tests are out of range investigation is required.

9.6 In addition to routine QC testing, test each new batch of Mueller-Hinton agar to ensure that all zones are within range.

Aminoglycosides may disclose unacceptable variation in divalent cations in the medium, tigecycline may disclose variation in magnesium, trimethoprimsulfamethoxazole will show up problems with the thymine content, erythromycin can disclose an unacceptable $\mathrm{pH}$. 


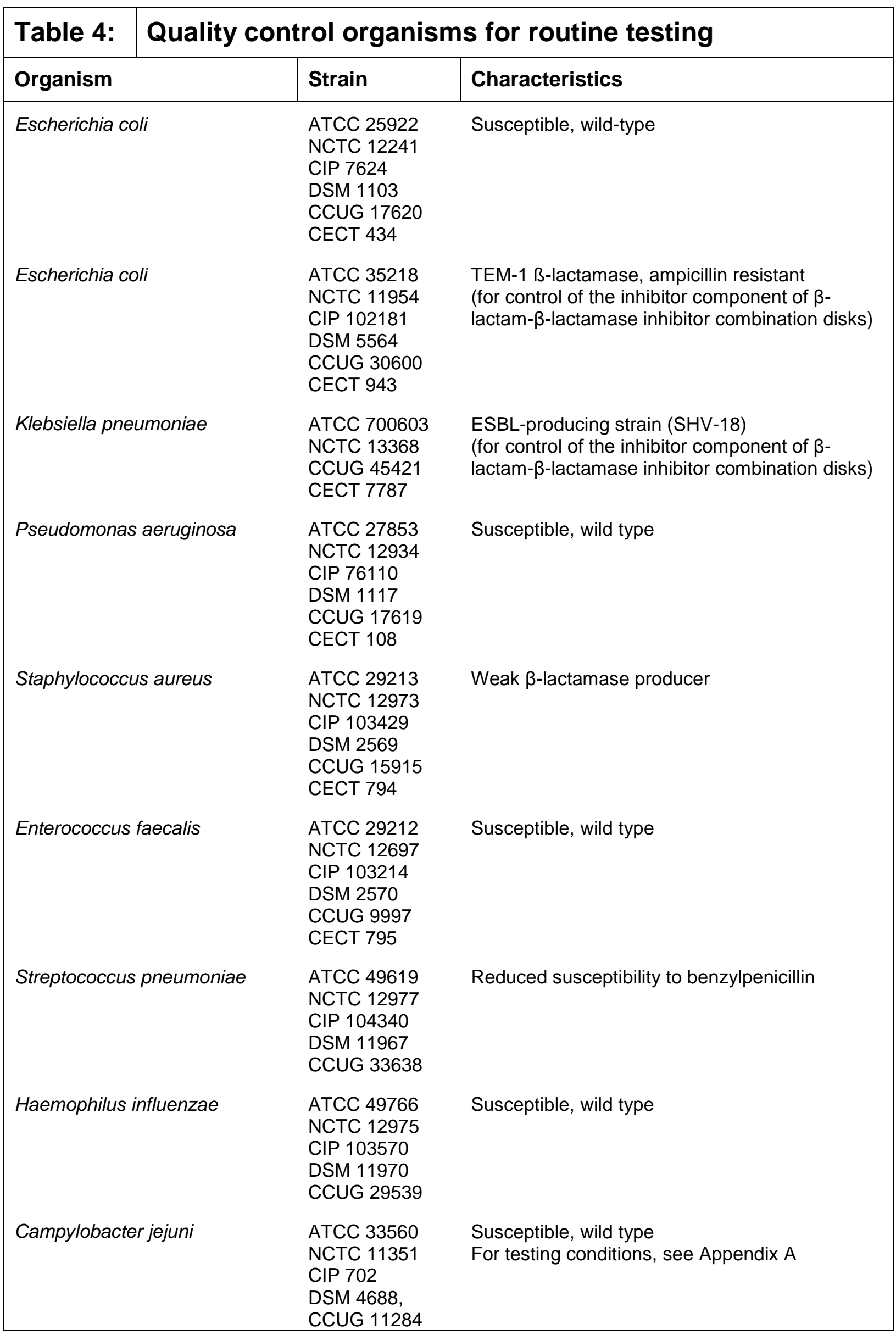

EUCAST Disk Diffusion Method for Antimicrobial Susceptibility Testing 


\begin{tabular}{|c|c|c|c|}
\hline Table 5: & \multicolumn{3}{|c|}{$\begin{array}{l}\text { Additional quality control organisms for detection of } \\
\text { specific resistance mechanisms (extended QC) }\end{array}$} \\
\hline \multicolumn{2}{|l|}{ Organism } & Strain & Characteristics \\
\hline \multicolumn{2}{|c|}{ Klebsiella pneumoniae } & $\begin{array}{l}\text { ATCC } 700603 \\
\text { NCTC } 13368 \\
\text { CCUG } 45421 \\
\text { CECT } 7787\end{array}$ & ESBL-producing strain (SHV-18) \\
\hline \multicolumn{2}{|c|}{ Staphylococcus aureus } & NCTC 12493 & mecA positive, hetero-resistant MRSA \\
\hline \multicolumn{2}{|c|}{ Enterococcus faecalis } & $\begin{array}{l}\text { ATCC } 51299 \\
\text { NCTC } 13379 \\
\text { CIP } 104676 \\
\text { DSM } 12956 \\
\text { CCUG } 34289\end{array}$ & $\begin{array}{l}\text { High-level aminoglycoside resistant (HLAR) and } \\
\text { vancomycin resistant (vanB positive) }\end{array}$ \\
\hline \multicolumn{2}{|c|}{ Haemophilus influenzae } & $\begin{array}{l}\text { ATCC } 49247 \\
\text { NCTC } 12699 \\
\text { CIP } 104604 \\
\text { DSM } 9999 \\
\text { CCUG } 26214\end{array}$ & $\begin{array}{l}\text { Reduced susceptibility to } \beta \text {-lactam agents due to } \\
\text { PBP mutations ( } \beta \text {-lactamase negative, ampicillin } \\
\text { resistant, BLNAR) }\end{array}$ \\
\hline
\end{tabular}




\section{Appendix A}

\section{Disk diffusion testing of Campylobacter jejuni and coli}

The following methodology (Table A1) must be adhered to when performing disk diffusion testing of Campylobacter jejuni and coli according to EUCAST.

\begin{tabular}{|c|c|}
\hline Table A1 & $\begin{array}{l}\text { Disk diffusion methodology for Campylobacter jejuni } \\
\text { and coli }\end{array}$ \\
\hline Medium & $\begin{array}{l}\text { Mueller-Hinton agar supplemented with } 5 \% \text { defibrinated horse blood and } 20 \\
\text { mg/L } \beta-N A D(M H-F) \\
\text { In order to reduce swarming, the } \mathrm{MH}-\mathrm{F} \text { plates should be dried prior to } \\
\text { inoculation (at } 20-25^{\circ} \mathrm{C} \text { overnight, or at } 35^{\circ} \mathrm{C} \text {, with the lid removed, for } 15 \\
\text { min). }\end{array}$ \\
\hline Inoculum & 0.5 McFarland \\
\hline Incubation & $\begin{array}{l}\text { Microaerobic environment } \\
41 \pm 1^{\circ} \mathrm{C} \\
24 \mathrm{~h} \\
\text { Incubation should result in confluent growth. Some } C \text {. coli isolates may not } \\
\text { have sufficient growth after } 24 \mathrm{~h} \text { incubation. These are re-incubated } \\
\text { immediately and inhibition zones read after a total of } 40-48 \mathrm{~h} \text { incubation. } \\
\text { An incubation temperature of } 41 \pm 1^{\circ} \mathrm{C} \text { was chosen to create favourable } \\
\text { conditions for growth of } C a m p y l o b a c t e r \text { spp. }\end{array}$ \\
\hline Reading & $\begin{array}{l}\text { Standard EUCAST reading instructions are used: } \\
\text { Read MH-F plates from the front with the lid removed and with reflected light. } \\
\text { Zone edges should be read at the point of complete inhibition as judged by } \\
\text { the naked eye with the plate held about } 30 \mathrm{~cm} \text { from the eye. }\end{array}$ \\
\hline $\begin{array}{l}\text { Quality } \\
\text { Control }\end{array}$ & Campylobacter jejuni ATCC 33560 \\
\hline
\end{tabular}


X EUCAST

European Society of Clinical Microbiology and Infectious Diseases 